\title{
Defunctioning stoma and short- and long-term outcomes after low anterior resection for rectal cancer-a nationwide register-based cohort study
}

\author{
Soran Gadan ${ }^{1,2}$ (I) J Judith S. Brand ${ }^{3} \cdot$ Martin Rutegård $^{4,5} \cdot$ Peter Matthiessen ${ }^{1,2}$ \\ Accepted: 2 February 2021 / Published online: 17 March 2021 \\ (C) The Author(s) 2021
}

\begin{abstract}
Purpose A defunctioning stoma reduces the risk of symptomatic anastomotic leakage after low anterior resection for rectal cancer and mitigates the consequences when a leakage occurs, but the impact on mortality and oncological outcomes is unclear. The aim was to investigate the associations of a defunctioning stoma with short- and long-term outcomes in patients undergoing low anterior resection for rectal cancer.

Methods Data from all patients who underwent curative low anterior resection for rectal cancer between 1995 and 2010 were obtained from the Swedish Colorectal Cancer Register. A total of 4130 patients, including 2563 with and 1567 without a defunctioning stoma, were studied. Flexible parametric models were used to estimate hazard ratios for all-cause mortality, 5year local recurrence, and distant metastatic disease in relation to the use of defunctioning stoma, adjusting for confounding factors and accounting for potential time-dependent effects.

Results During a median follow-up of 8.3 years, a total of 2169 patients died. In multivariable analysis, a relative reduction in mortality was observed up to 6 months after surgery (hazard ratio $=0.82: 95 \%$ CI $0.67-0.99$ ), but not thereafter. After 5 years of follow-up, 4.2\% (173/4130) of the patients had a local recurrence registered and 17.9\% (741/4130) had developed distant metastatic disease, without difference between patients with and without defunctioning stoma.

Conclusion A defunctioning stoma is associated with a short-term reduction in all-cause mortality in patients undergoing low anterior resection for rectal cancer without any difference in long-term mortality and oncological outcomes, and should be considered as standard of care.
\end{abstract}

Keywords Anastomotic leakage $\cdot$ Defunctioning stoma $\cdot$ Rectal cancer

This manuscript has been presented in parts at the Swedish Surgical week, Norrköping, Sweden, August 19-23, 2019 and at the European Society of Coloproctology meeting, Vienna, Austria, September 25-27, 2019.

Soran Gadan

soran.gadan@regionorebrolan.se

1 Department of Surgery, Örebro University Hospital, Örebro, Sweden

2 Department of Surgery, Faculty of Medicine and Health, Örebro University, Örebro, Sweden

3 Clinical Epidemiology and Biostatistics, School of Medical Sciences, Örebro University, Örebro, Sweden

4 Surgical and Perioperative Sciences, Surgery, Umeå University, Umeå, Sweden

5 Wallenberg Center for Molecular Medicine, Umeå University, Umeå, Sweden

\section{Introduction}

In the past decades, the survival rate after rectal cancer treatment has increased and local recurrence rates have decreased. Important reasons for these achievements have been the introduction of total mesorectal excision (TME) and neoadjuvant therapy [1-3]. In patients with low and mid rectal cancer, TME with an anastomosis at the pelvic floor, also labeled as low anterior resection of the rectum (LAR), is currently the standard surgical procedure. Despite these treatment advancements, adverse events are common with the most feared being anastomotic leakage, which often has been reported to occur in approximately 10 to $12 \%$ of all patients undergoing LAR [4-6]. Possible consequences of anastomotic leakage include pelvic sepsis, the need for urgent reoperation, multi-organ failure, increased short-term postoperative mortality, and an increased risk for a permanent stoma $[7,8]$. 
The main reason for constructing a defunctioning stoma in LAR is to decrease the risk of symptomatic anastomotic leakage, as well as moderating the adverse consequences when anastomotic leakage occurs despite defunctioning of the low colorectal anastomosis [9-11]. Several studies have demonstrated the benefit of a defunctioning stoma, as reflected by lower rates of symptomatic anastomotic leakage, urgent reoperation, and early postoperative mortality [9, 10, 12-14]. For these reasons, the use of routine defunctioning stoma in LAR has become widespread practice. Nevertheless, a defunctioning stoma is also associated with various adverse events including high stoma output, dehydration, bowel obstruction, parastomal hernia, and an increased risk of stoma permanence [15-21]. To date, few studies have examined whether or not a defunctioning stoma influences long-term oncological outcomes. Current evidence regarding the potential long-term impact of symptomatic anastomotic leakage in patients undergoing LAR is also conflicting [22-25].

The aim of this large population-based study using nationwide register-based data was to compare the short- and longterm outcomes in patients undergoing LAR with and without a defunctioning stoma in terms of all-cause mortality, local recurrence, and distant metastatic disease.

\section{Methods}

The present study uses data from a national register-based cohort of patients who underwent anterior resection for rectal cancer in Sweden between 1995 and 2010, all registered in the Swedish Colorectal Cancer Registry (SCRCR). The SCRCR is a national quality register that prospectively records information on variables related to patient demography, surgical and perioperative details, neoadjuvant and adjuvant treatment, postoperative events, and short- and long-term oncological outcomes. Nearly all patients $(99 \%)$ diagnosed with adenocarcinoma of the rectum in Sweden have been registered since the start of the register in 1995 [26]. Some validation studies of the SCRCR have been conducted with the latest report, Moberger et al. in 2018, demonstrating high accuracy for most relevant variables [26-28].

In this study, the aim was to include exclusively patients having undergone sphincter-saving TME surgery with an anastomosis on the pelvic floor, also labeled as LAR. Between 1995 and 2010, a total of 19,359 patients underwent abdominal resection for rectal cancer in Sweden: anterior resection ( $n=10,811)$, abdominoperineal excision (APE; $n=$ 5938), and Hartmann's procedure $(n=2610)$. Only patients undergoing anterior resection were assessed for the present study. Anastomotic height is not a registered variable in the SCRCR and therefore, tumor height was deemed the best proxy for anastomotic level.
Patients with a tumor level of 4 to $10 \mathrm{~cm}$ from the anal verge were identified and included. Patients with a tumor level of $\geq 11 \mathrm{~cm}(n=5025)$ were deemed less likely to have an anastomosis at the pelvic floor, and were therefore excluded. Patients with a tumor level of $\leq 3 \mathrm{~cm}$ above the anal verge were arbitrarily excluded $(n=84)$ as it was deemed that there was a potential risk of misclassification (APE, or possibly Hartmann's procedure, incorrectly registered as LAR). We further employed the following exclusion criteria: cancer stage IV, patients registered with macroscopically or microscopically not radical resection, unclear resection margin as assessed intraoperatively by the surgeon, bowel perforation near the tumor, emergency surgery, and cases where data on defunctioning stoma or tumor level were missing (Fig. 1). After these exclusions, the study population for analysis consisted of 4130 stage I-III rectal cancer patients having undergone curative LAR, including 2563 with a defunctioning stoma at index surgery and 1567 without defunctioning stoma at index surgery. Permission for the study was obtained by the Uppsala Regional Ethics Review Board, Uppsala, Sweden (Dnr 2014/470).

\section{Patient characteristics, operative details, and postoperative outcome}

The following variables were extracted from the SCRCR for descriptive statistics and/or inclusion in multivariable analyses: age, sex, clinical cancer stage (cTNM), tumor level, neoadjuvant therapy, adjuvant therapy, and year of surgery. Perioperative variables included duration of surgery, intraoperative blood loss, defunctioning stoma at index surgery, postoperative adverse events including symptomatic anastomotic leakage, hospital stay, and postoperative mortality.

Surgical and medical complications diagnosed within 30 days of index surgery are registered in the SCRCR. The SCRCR has no formal definition of anastomotic leakage, and any leakage diagnosed within 30 days of index surgery should be registered. It can therefore be assumed that registered leaks were symptomatic/clinical, and that asymptomatic/ subclinical leaks may have been registered only to a negligible degree.

From 2007 onwards, the SCRCR also records BMI and the American Society of Anesthesiologists (ASA) comorbidity grade. As our study population included patients operated between 1995 and 2010, this information was only available in $23 \%(951 / 4130)$ of the patients.

\section{Long-term outcomes}

Information on all-cause mortality is available for all registered patients through linkage to the Swedish Cause of Death register, and 5-year data on local recurrence and distant metastatic disease are directly recorded in the SCRCR. Local 
Rectal cancer patients undergoing anterior resection between 1995 and 2010 , $\mathrm{n}=10811$

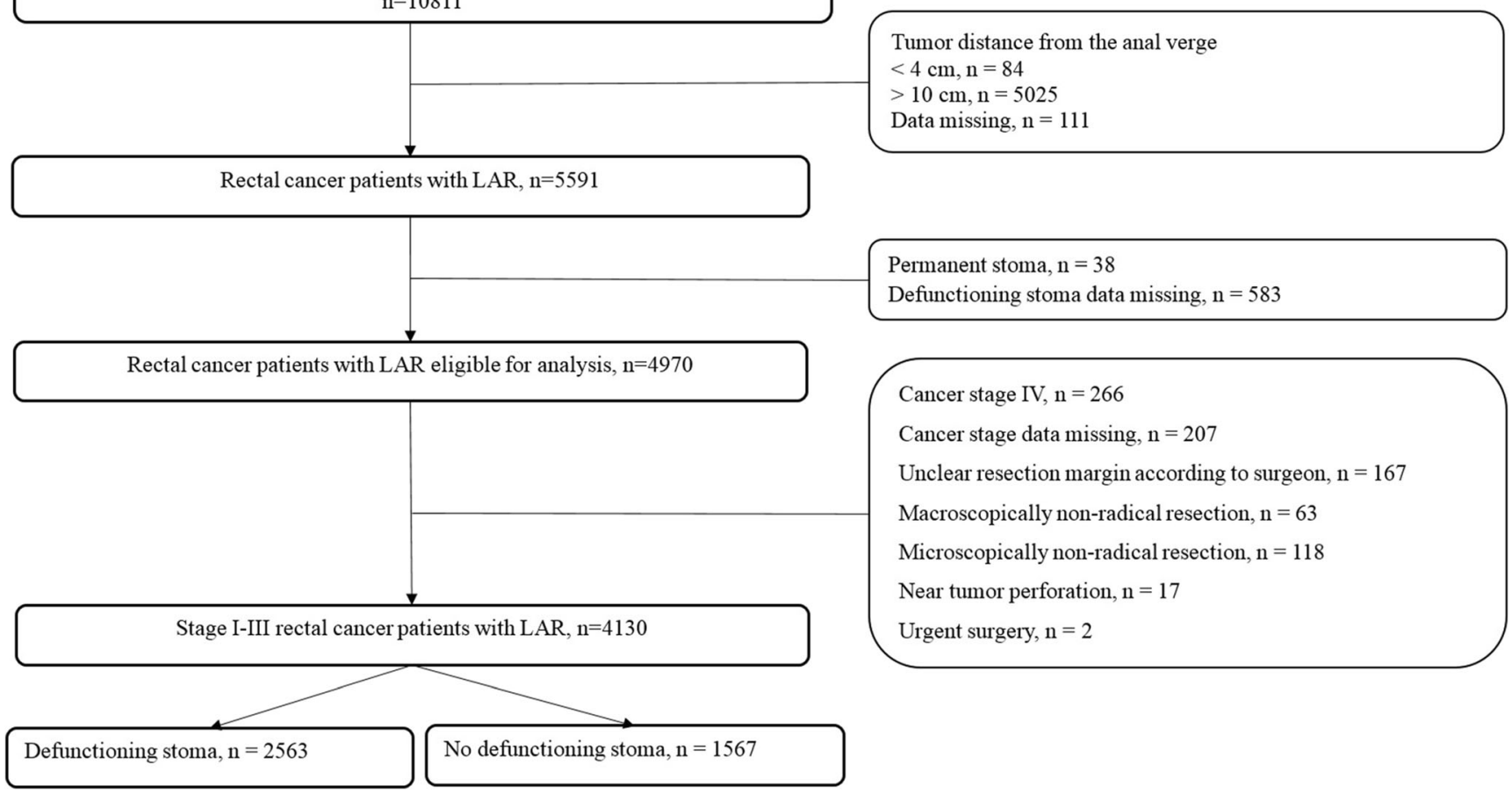

Fig. 1 Flow chart of the study population of patients operated with low anterior resection for rectal cancer in Sweden between 1995 and 2010. Defunctioning stoma was registered in the SCRCR by all health care regions from 1998 onwards

recurrence is defined in the SCRCR as any recurrence of previously operated rectal adenocarcinoma located in the pelvic cavity [29]. In a validation report by Jörgren et al., including patients operated between 1995 and 1997, 89\% of the local recurrence cases found in all medical records were also registered in the SCRCR [27]. To our knowledge, no published validation data exist for distant metastatic disease.

\section{Statistical analysis}

Distributions of patient characteristics in relation to the presence of a defunctioning stoma or not were compared using chi-square tests for categorical variables, while Student's $t$ test and Mann-Whitney $U$ test were employed for continuous variables, as appropriate. Study endpoints for analyses were time to death from any cause, time to local recurrence, and time to distant metastatic disease. For each of these endpoints, followup time was defined from the date of index surgery (LAR) until the event, emigration, death, or date of last follow-up (31 December 2016), whichever came first. When analyzing time to local recurrence and metastatic disease, death was treated as a competing event and follow-up was additionally censored 5 years after the index surgery. Five-year cumulative incidence curves for local recurrence and distant metastatic disease to summarize absolute risks of disease recurrence in relation to defunctioning stoma are also presented.
Flexible parametric models were used to estimate the association between the use of a defunctioning stoma and each of the study endpoints $[30,31]$. The proportional hazards assumption was tested using likelihood ratio tests of time by covariate interactions. As with the Cox regression model, flexible parametric models yield hazard ratios (HRs) as relative measures of association, but also allow the association with the exposure (i.e., defunctioning stoma) to vary over time (i.e., non-proportional). Under the proportional hazards assumption, HRs estimated with these models are similar to those obtained from the Cox model. In all models, time since surgery was the underlying time scale and a restricted cubic spline with five degrees of freedom was used for the baseline hazard. In case of non-proportionality, time-dependent effects were modeled by adding an interaction term with time using a second spline with three degrees of freedom. To facilitate comparison across analysis models, HRs were also reported at different time points following surgery, for each month during the first year, and at 2, 5, 10, and 15 years after surgery.

All analyses were adjusted for calendar year of surgery to account for cohort effects in defunctioning stoma prevalence as well as survival and recurrence rates during the study period (model 1). Analyses were further adjusted for all observed potential confounders in a multivariable adjusted model including age, sex, cancer stage, tumor level, neoadjuvant therapy, and year of surgery (model 2). A sensitivity analysis was also performed to evaluate possible residual confounding by 
BMI and ASA comorbidity grade, by repeating the multivariable adjusted model (model 2) in the subcohort of patients operated between 2007 and 2010 with additional adjustment for these variables (model 3). All data were analyzed using Stata version 16 (StataCorp, College Station, TX, USA).

\section{Results}

\section{Patient characteristics, operative details, and postoperative outcomes}

Patients with a defunctioning stoma at index surgery were younger (mean age 66.4 compared with 68.3 years), more often male (61.1\% and 49.6\%), had a lower tumor level (mean 8.1 compared with $8.5 \mathrm{~cm}$ ), and more often received neoadjuvant therapy (76.8\% and 62.9\%), respectively, as compared with those without defunctioning stoma. The use of a defunctioning stoma at index surgery increased over time during the study period. Distributions of other patient characteristics were comparable between the two groups.

Patients with a defunctioning stoma had increased intraoperative blood loss (median $600 \mathrm{~mL}$ compared with $500 \mathrm{~mL}$ ). The rate of symptomatic anastomotic leakage was lower in patients with defunctioning stoma compared to that in those without (9.5\% and $14.7 \%$, respectively). Hospital stay was longer for those with a defunctioning stoma at index surgery. Early postoperative mortality was lower in those with defunctioning stoma at index surgery as compared with those without, 30-day mortality was $0.9 \%$ and $1.8 \%$, respectively, and 90 -day mortality was $1.8 \%$ and $3.6 \%$, respectively (Table 1).

Only a small number of patients, $0.5 \%$ (21/4130), had missing covariate data and all associations with oncological outcomes presented are therefore based on complete case data.

\section{Mortality and long-term oncological outcomes}

Overall, 2169 patients died during a median follow-up of 8.3 (interquartile range 4.7 to 12.4 ) years. Tests for proportional hazards revealed that the association between defunctioning stoma and all-cause mortality was not constant over time. In analyses adjusting for year of surgery, patients with a defunctioning stoma had a lower mortality rate early after surgery than those without (HR at 6 months $0.79 ; 95 \%$ CI: 0.67 to 0.92 , and at 1 year $0.81 ; 95 \%$ CI: $0.68-0.96$ ), while no long-term difference in mortality was found (Tables 2 and 3; Figs. 2 and 3). Estimates were not very different in multivariable adjusted analyses except for the association with mortality only being statistically significant up to 6 months (HR at 6 months $=0.82 ; 95 \%$ CI 0.67 to 0.99 and at 1 year $=0.88(0.75$; $1.03)$ ). After 5 years, $4.2 \%$ (173/4130) of the patients had a local recurrence registered and $17.9 \%(741 / 4130)$ had metastatic disease. No evidence of non-proportional hazards was found for these study endpoints. The cumulative incidence curves for local recurrence and distant metastatic disease by defunctioning stoma are presented in Fig. 4. The 5year cumulative incidence for local recurrence in patients with and without a defunctioning stoma was $3.9 \%$ (95\% CI: 3.2 to $4.7 \%$ ) and $4.6 \%$ (95\% CI: 3.6 to $5.6 \%$ ), respectively. Corresponding estimates for distant metastatic disease were $18.3 \%$ (95\% CI: 16.7 to $19.7 \%$ ) and $17.5 \%$ (95\% CI: 15.6 to $19.3 \%$ ), respectively. Multivariable analyses yielded similar results, with no evidence of a risk difference in local recurrence $(\mathrm{HR}=1.00 ; 95 \% \mathrm{CI}: 0.72$ to 1.39$)$ and distant metastatic disease (HR $=1.03 ; 95 \%$ CI: 0.87 to 1.21 ) when comparing patients with and without a defunctioning stoma (Table 4).

HRs for all study endpoints, i.e., all-cause mortality, local recurrence, and distant metastatic disease, were not notably different after additional adjustment for BMI and ASA except for confidence intervals being wider given the smaller number of patients and events included in this analysis (Tables 5 and $6)$.

\section{Discussion}

The present study demonstrates that short-term all-cause mortality was lower in patients undergoing LAR for cancer with a defunctioning stoma at index surgery, compared with that in those without an initial defunctioning stoma. More specifically, patients with a defunctioning stoma at index surgery had a lower mortality rate up to 6 months after surgery. No differences in long-term overall mortality, nor oncological outcome with regard to 5-year local recurrence or metastatic disease, were found between patients with and without a defunctioning stoma at index surgery.

\section{Strengths and limitations}

This is a large study addressing long-term oncological outcomes in rectal cancer patients undergoing LAR in relation to the presence of a defunctioning stoma. The present study has several strengths. First, the nationwide register-based design with prospective data collection and complete follow-up in a large population-based sample minimizes the risk of selection and information biases. However, despite the high degree of coverage of the SCRCR, some shortcomings of the register have been reported [28, 32]. For instance, anastomotic level is not registered in the SCRCR and we therefore used the tumor height as a proxy for LAR. This strategy of excluding patients with a tumor level of more than $10 \mathrm{~cm}(n=5025)$ may not have resulted in the exclusion of all patients with an anastomosis above the pelvic floor, perhaps more likely in women, but we deem that the vast majority of patients included in the present study in fact underwent LAR. A limited number of 
Table 1 Patient characteristics, operative details, and postoperative outcomes in patients operated with low anterior resection for rectal cancer with and without a planned defunctioning stoma

\begin{tabular}{|c|c|c|c|c|}
\hline & \multirow{2}{*}{$\begin{array}{l}\text { All } \\
(n=4130)\end{array}$} & \multicolumn{2}{|c|}{ Defunctioning stoma } & \multirow[b]{2}{*}{$p$ value } \\
\hline & & No $(n=1567)$ & Yes $(n=2563)$ & \\
\hline \multicolumn{5}{|l|}{ Age (years), $\%(N)$} \\
\hline$<65$ & $37.1(1534)$ & $34.3(538)$ & $38.9(996)$ & \multirow[t]{3}{*}{$<0.001$} \\
\hline $65-75$ & $39.4(1628)$ & $36.8(576)$ & $41.0(1052)$ & \\
\hline$>75$ & $23.4(968)$ & $28.9(453)$ & $20.1(515)$ & \\
\hline Mean, SD & $67.1(10.6)$ & $68.3(10.8)$ & $66.4(10.5)$ & $<0.001$ \\
\hline Male sex, $\%(N)$ & $56.8(2345)$ & $49.6(778)$ & $61.1(1567)$ & $<0.001$ \\
\hline \multicolumn{5}{|c|}{ ASA comorbidity grade, $\%(N)^{*}$} \\
\hline 1 & $29.2(302)$ & $22.1(23)$ & $30.0(279)$ & \multirow{4}{*}{0.22} \\
\hline 2 & $58.2(602)$ & $65.4(68)$ & $57.4(534)$ & \\
\hline$\geq 3$ & $12.6(130)$ & $12.5(13)$ & $12.6(117)$ & \\
\hline Missing & $75.0(3096)$ & $93.4(1463)$ & $63.7(1633)$ & \\
\hline \multicolumn{5}{|l|}{ BMI $\left(\mathrm{kg} / \mathrm{m}^{2}\right)^{*}$} \\
\hline Mean, SD & $25.5(3.9)$ & $25.1(4.6)$ & $25.6(3.8)$ & \multirow[t]{2}{*}{0.24} \\
\hline Missing, \% $(N)$ & $76.5(3160)$ & $93.3(1462)$ & $66.3(1698)$ & \\
\hline \multicolumn{5}{|l|}{ Tumor level (cm) } \\
\hline Mean (SD) & $8.2(1.8)$ & $8.5(1.7)$ & $8.1(1.8)$ & $<0.001$ \\
\hline \multicolumn{5}{|l|}{ Cancer stage, $\%(N)$} \\
\hline I & $31.7(1309)$ & $31.9(500)$ & $31.6(809)$ & \multirow[t]{3}{*}{0.37} \\
\hline II & $32.0(1322)$ & $33.1(518)$ & $31.4(804)$ & \\
\hline III & $36.3(1499)$ & $35.0(549)$ & $37.1(950)$ & \\
\hline \multicolumn{5}{|c|}{ No. of positive lymph nodes, \% $(N)$} \\
\hline 0 & $62.9(1890)$ & $64.9(699)$ & $61.7(1191)$ & \multirow[t]{4}{*}{0.22} \\
\hline $1-3$ & $23.7(714)$ & $22.4(241)$ & $24.5(473)$ & \\
\hline$\geq 4$ & $13.4(403)$ & $12.7(137)$ & $13.8(266)$ & \\
\hline Missing & $27.2(1123)$ & $31.3(490)$ & $24.7(633)$ & \\
\hline \multicolumn{5}{|l|}{ Neoadjuvant therapy, \% $(N)$} \\
\hline None & $28.4(1169)$ & $37.1(577)$ & $23.2(592)$ & \multirow[t]{4}{*}{$<0.001$} \\
\hline Radiotherapy & $67.5(2775)$ & $62.4(971)$ & $70.7(1804)$ & \\
\hline Radio plus chemotherapy & $4.0(165)$ & $0.6(9)$ & $6.1(156)$ & \\
\hline Missing & $0.5(21)$ & $0.6(10)$ & $0.4(11)$ & \\
\hline \multicolumn{5}{|l|}{ Intraoperative bleeding $(\mathrm{mL})$} \\
\hline Median, (Q1- Q3) & $600(300 ; 1000)$ & $500(300 ; 900)$ & $600(350 ; 1000)$ & \multirow[t]{2}{*}{$<0.001$} \\
\hline Missing, $\%(N)$ & $21.7(898)$ & $34.5(541)$ & $13.9(357)$ & \\
\hline \multicolumn{5}{|c|}{ Symptomatic anastomotic leakage, $\%(N)$} \\
\hline No & $88.5(3656)$ & $85.3(1337)$ & $90.5(2319)$ & \multirow[t]{2}{*}{$<0.001$} \\
\hline Yes & $11.5(474)$ & $14.7(230)$ & $9.5(244)$ & \\
\hline \multicolumn{5}{|c|}{ Length of in hospital stay (days) } \\
\hline Median, (Q1-Q3) & $10(8 ; 15)$ & $9(7 ; 14)$ & $11(8 ; 16)$ & \multirow[t]{2}{*}{$<0.001$} \\
\hline Missing, $\%(N)$ & $0.2(10)$ & $0.3(5)$ & $0.2(5)$ & \\
\hline 30-day mortality, \% $(N)$ & $1.4(59)$ & $2.3(36)$ & $0.9(23)$ & $<0.001$ \\
\hline 90 -day mortality, \% $(N)$ & $2.5(102)$ & $3.6(57)$ & $1.8(45)$ & $<0.001$ \\
\hline \multicolumn{5}{|c|}{ Calendar year of surgery, $\%(N)$} \\
\hline $1995-2000$ & $31.1(1283)$ & $41.2(646)$ & $24.9(637)$ & $<0.001$ \\
\hline 2001-2005 & $35.7(1474)$ & $46.3(726)$ & $29.2(748)$ & \\
\hline 2006-2010 & $33.2(1373)$ & $12.4(195)$ & $46.0(1178)$ & \\
\hline
\end{tabular}

$L A R$, low anterior resection; $S D$, standard deviation; $Q 1$, quartile 1; $Q 3$, quartile 3; $A S A$, American Society of Anesthesiologists; $B M I$, body mass index. *BMI and ASA are recorded in the SCRCR from 2007 onwards

*Number of lymph nodes was recorded in the SCRCR by some health care regions from 1995 and by all health care regions $(n=6)$ from 2003 onwards

patients $(n=84)$ with a registered tumor height at $1-3 \mathrm{~cm}$ above the anal verge were arbitrarily excluded due to the potential risk of misclassification regarding surgical procedure (LAR registered instead of APE or possibly Hartmann's procedure). Furthermore, SCRCR validation data for long-term oncological outcomes are limited. We acknowledge the risk of underreporting of local recurrences to some extent. However, any underreporting is unlikely to be related to whether a defunctioning stoma at index surgery was placed or not, and as such has probably resulted in an underestimation of associations observed as this weakens the validity of the negative finding in this study, due to random rather than systematic misclassification. Lastly, we adjusted our analyses for a comprehensive set of observed confounders, but as this is an observational study, we cannot rule out residual confounding. 
Table 2 Hazard ratios for all-cause mortality associated with planned defunctioning stoma at different time points following surgery in patients operated with low anterior resection for rectal cancer

\begin{tabular}{|c|c|c|c|c|c|c|c|}
\hline & \multirow[b]{2}{*}{$N$ all/deaths } & \multicolumn{6}{|l|}{$\mathrm{HR}(95 \% \mathrm{CI})$} \\
\hline & & At 6 months & At 1 year & At 2 years & At 5 years & At 10 years & At 15 years \\
\hline \multicolumn{8}{|c|}{ Model 1 defunctioning stoma } \\
\hline No & $1567 / 940$ & REF & REF & REF & REF & REF & REF \\
\hline Yes & $2563 / 1229$ & $0.75(0.61 ; 0.92)$ & $0.81(0.68 ; 0.96)$ & $0.90(0.78 ; 1.05)$ & $1.07(0.94 ; 1.21)$ & $1.07(0.94 ; 1.22)$ & $1.01(0.81 ; 1.28)$ \\
\hline \multicolumn{8}{|c|}{ Model 2 defunctioning stoma } \\
\hline No & $1557 / 933$ & REF & REF & REF & REF & REF & REF \\
\hline Yes & $2552 / 1221$ & $0.82(0.67 ; 0.99)$ & $0.88(0.75 ; 1.03)$ & $0.97(0.84 ; 1.11)$ & $1.06(0.95 ; 1.18)$ & $1.05(0.93 ; 1.20)$ & $1.05(0.89 ; 1.25)$ \\
\hline
\end{tabular}

HRs were estimated from flexible parametric models with time since surgery as underlying time scale, not assuming proportional hazards (allowing HRs to vary over time)

Model 1: adjusted for year of surgery

Model 2: adjusted for age, sex, cancer stage, tumor level, neoadjuvant therapy, and year of surgery

$H R$, hazard ratio; $C I$, confidence interval

\section{Comparison with previous studies}

Evidence from randomized clinical trials shows that a defunctioning stoma reduces the rate of symptomatic anastomotic leakage in rectal patients undergoing LAR $[10,11,33]$. Consistent with this evidence, we found a lower anastomotic leakage rate in patients with a defunctioning stoma compared to those without (9.5\% and $14.7 \%$, respectively). This crude estimate corresponds to a relative risk reduction of $35 \%$, which, although substantial, is lower than the reduction seen in randomized trials assessing defunctioning stomas in LAR $[10,11,33]$. Also, the crude estimate reported here is not directly comparable to estimates observed in randomized trials, which, by design, control for confounding by measured and unmeasured factors. Moreover, we acknowledge that there may be some underreporting of anastomotic leakage in the SCRCR, as in contrast to prospective randomized controlled trials. However, the use of defunctioning stomas in this study cohort was at the discretion of the surgical team, leading to a considerable case-mix, for instance a larger proportion of neoadjuvant therapy in the stoma group, which explains the relatively lesser degree of leakage reduction $[10,11]$.

As symptomatic anastomotic leakage is associated with severe adverse events such as peritonitis and sepsis, a shortterm survival benefit in patients receiving a defunctioning stoma at index surgery is considered plausible. A defunctioning stoma also mitigates the clinical consequences when a symptomatic leakage occurs, and could thereby also reduce mortality in this particular group of patients. In our study, 30-day and 90-day mortality rates were lower in patients with a defunctioning stoma at index surgery compared to those without, a finding that is in agreement with meta-

Table 3 Multivariable adjusted hazard ratios for all-cause mortality associated with defunctioning stoma within the first year of follow-up in patients operated with low anterior resection for rectal cancer

\begin{tabular}{|c|c|c|c|c|c|c|}
\hline & \multicolumn{6}{|l|}{$\operatorname{HR}(95 \% \mathrm{CI})$} \\
\hline & At 1 month & At 2 months & At 3 months & At 4 months & At 5 months & At 6 months \\
\hline \multicolumn{7}{|c|}{ Model 2 defunctioning stoma } \\
\hline No & REF & REF & REF & REF & REF & REF \\
\hline \multirow[t]{2}{*}{ Yes } & $0.51(0.32 ; 0.81)$ & $0.60(0.40 ; 0.91)$ & $0.69(0.51 ; 0.95)$ & $0.76(0.59 ; 0.97)$ & $0.79(0.64 ; 0.98)$ & $0.82(0.67 ; 0.99)$ \\
\hline & At 7 months & At 8 months & At 9 months & At 10 months & At 11 months & At 12 months \\
\hline \multicolumn{7}{|c|}{ Model 2 defunctioning stoma } \\
\hline No & REF & REF & REF & REF & REF & REF \\
\hline Yes & $0.83(0.70 ; 1.00)$ & $0.85(0.71 ; 1.01)$ & $0.86(0.73 ; 1.01)$ & $0.87(0.74 ; 1.02)$ & $0.87(0.74 ; 1.02)$ & $0.88(0.75 ; 1.03)$ \\
\hline
\end{tabular}

HRs were estimated from flexible parametric models with time since surgery as underlying time scale, not assuming proportional hazards (allowing HRs to vary over time)

Model 2: adjusted for age, sex, cancer stage, tumor level, neoadjuvant therapy, and year of surgery

$H R$, hazard ratio; $C I$, confidence interval 
Table 4 Hazard ratios for local recurrence and distant metastasis associated with planned defunctioning stoma in patients operated with low anterior resection for rectal cancer

\begin{tabular}{|c|c|c|c|c|}
\hline & \multicolumn{2}{|c|}{ Local recurrence } & \multicolumn{2}{|c|}{ Distant metastasis } \\
\hline & $N$ all/events & $\mathrm{HR}(95 \% \mathrm{CI})$ & $N$ all/events & $\mathrm{HR}(95 \% \mathrm{CI})$ \\
\hline \multicolumn{5}{|c|}{ Model 1 defunctioning stoma } \\
\hline No & $1567 / 72$ & REF (1.00) & $1567 / 274$ & REF (1.00) \\
\hline Yes & $2563 / 101$ & $1.02(0.74 ; 1.40)$ & $2563 / 467$ & $1.06(0.90 ; 1.25)$ \\
\hline \multicolumn{5}{|c|}{ Model 2 defunctioning stoma } \\
\hline No & $1557 / 72$ & REF (1.00) & $1557 / 273$ & REF (1.00) \\
\hline Yes & $2552 / 100$ & $1.00(0.72 ; 1.39)$ & $2552 / 466$ & $1.03(0.87 ; 1.21)$ \\
\hline
\end{tabular}

HRs were estimated from flexible parametric models with time since surgery as underlying time scale, assuming proportional hazards and accounting for the competing risk of death

Model 1: adjusted for year of surgery

Model 2: adjusted for age, sex, cancer stage, tumor level, neoadjuvant therapy, and year of surgery

$H R$, hazard ratio; $C I$, confidence interval

analysis results of observational data showing a consistent reduction in postoperative mortality in patients receiving a defunctioning stoma at index surgery $[5,13,34]$.

Previous observational studies and randomized clinical trials could not address differences in mortality by time since surgery and were unable to investigate differences in mortality beyond the initial postoperative time window. The present study therefore extends the available evidence base by showing that the overall reduction in all-cause mortality in patients with a defunctioning stoma persists up to 6 months after surgery, but not thereafter.

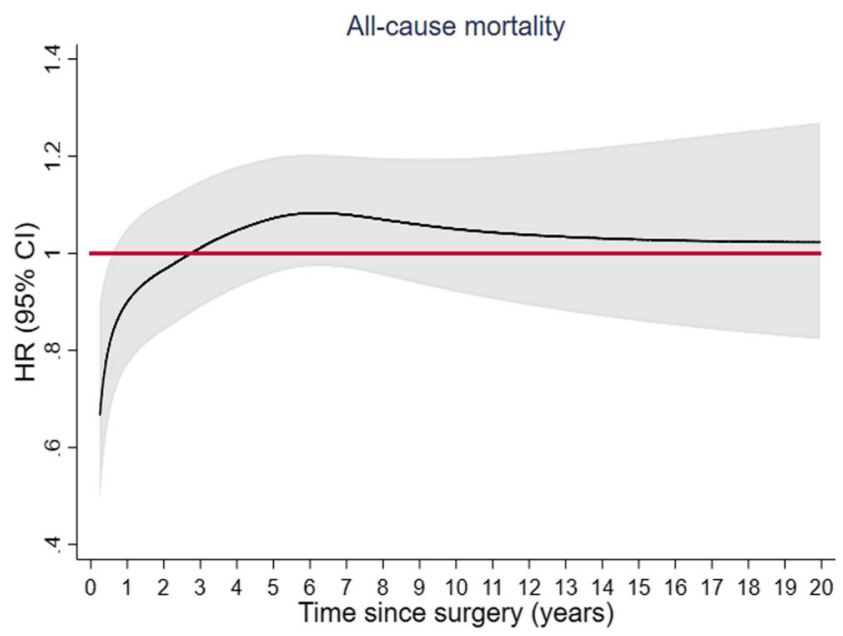

Fig. 2 Time-dependent hazard ratios for all-cause mortality associated with defunctioning stoma at index surgery in patients operated with low anterior resection for rectal cancer. Time-dependent HRs are adjusted for age, sex, cancer stage, tumor level, neoadjuvant therapy, and year of surgery (model 2). CI, confidence interval; HR, hazard ratio

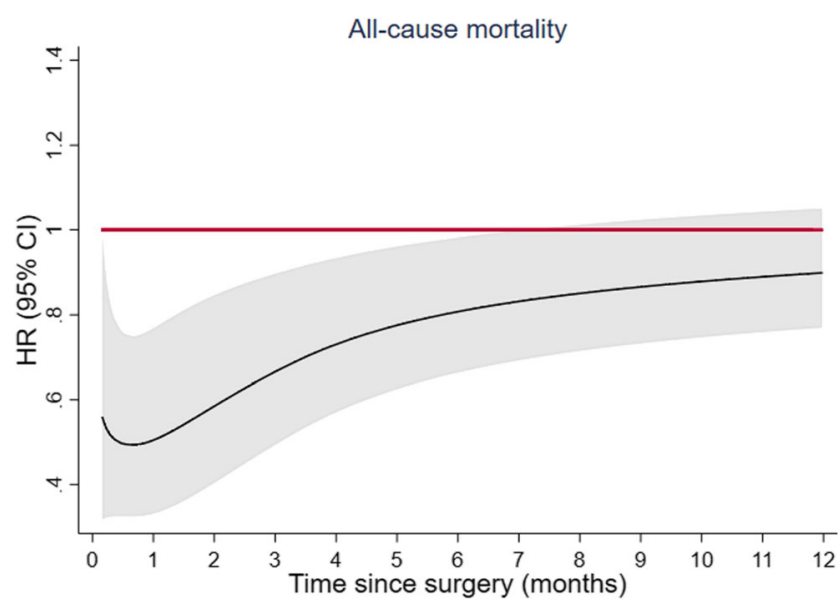

Fig. 3 Time-dependent hazard ratios for all-cause mortality associated with defunctioning stoma at index surgery in the first year following surgery in patients operated with low anterior resection for rectal cancer. Time-dependent HRs are adjusted for age, sex, cancer stage, tumor level, neoadjuvant therapy, and year of surgery (model 2). CI, confidence interval; HR, hazard ratio

Data concerning the association with disease recurrence are limited. A study by Smith et al., which used a similar registerbased design, found no difference in 5-year disease recurrence and overall survival in patients with and without a defunctioning stoma in stratified analyses. The aforementioned study had a sample size of one-fourth of our study, but its results are consistent with ours showing no association with long-term outcome. The evidence base regarding the association of anastomotic leakage with long-term oncological outcome is larger but conflicting, with studies showing either no difference in risk or an increased risk of specific oncological outcomes, mostly local recurrence and to a smaller extent cancer-specific mortality [22-25,35]. These discrepant results have been attributed to various factors, including the variability in diagnosis and management of leakages as well as heterogeneity in patient populations analyzed with the presence of residual disease being the strongest determinant of local recurrence risk [23, 36]. Findings observed for defunctioning stoma in our study appear to be consistent with results from studies in comparable rectal cancer patient populations with little evidence of residual disease, showing no difference in long-term oncological outcome with anastomotic leakage occurrence $[22,23]$.

\section{Implications}

Results of the present study demonstrate that, despite a shortterm mortality reduction, long-term all-cause mortality and disease recurrence are not affected by a defunctioning stoma in rectal cancer patients undergoing LAR. Overall, these findings support the use of a defunctioning stoma as standard of care in LAR. Nevertheless, a defunctioning stoma is 
Fig. 4 Cumulative incidence of local recurrence and distant metastatic disease in patients operated with low anterior resection for rectal cancer with and without defunctioning stoma at index surgery. Cumulative incidence curves with $95 \%$ confidence intervals for local recurrence and distant metastasis in patients with and without a defunctioning stoma were estimated from flexible parametric models assuming proportional hazards with death as competing event

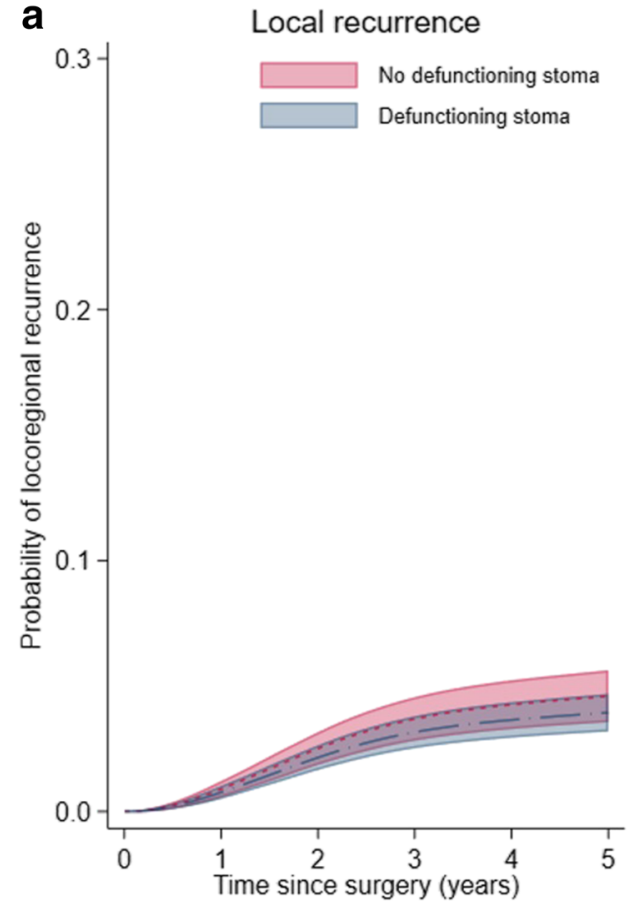

associated with numerous adverse events which, although different in nature, are generally less severe than those associated with a symptomatic anastomotic leakage [15-21]. It therefore seems relevant to attempt to individualize the routine use of a defunctioning stoma or not, balancing the risks of the stoma against the benefit of reductions in symptomatic anastomotic leakage and short-term mortality, also from a costeffectiveness perspective [37]. Future studies aiming at identifying patients in whom the preoperatively assessable risks do no outweigh the benefits using a defunctioning stoma are warranted, as well as research aimed at developing strategies to reduce the adverse events related to the defunctioning stoma itself.

\section{Conclusion}

Our findings demonstrate that a defunctioning stoma is associated with a short-term reduction in all-cause mortality in patients undergoing low anterior resection for rectal cancer, without any difference in long-term mortality and oncological outcome, and should be considered standard of care.

Table 5 Hazard ratios for all-cause mortality associated with planned defunctioning stoma at different time points in patients operated with low anterior resection for cancer. Sensitivity analysis

\begin{tabular}{|c|c|c|c|c|c|c|c|}
\hline & \multirow[b]{2}{*}{$N$ all/events } & \multicolumn{6}{|l|}{$\mathrm{HR}(95 \% \mathrm{CI})$} \\
\hline & & At 6 months & At 1 year & At 2 years & At 5 years & At 10 years & At 15 years \\
\hline \multicolumn{8}{|c|}{ Model 3 defunctioning stoma } \\
\hline No & $100 / 42$ & REF & REF & REF & REF & REF & REF \\
\hline Yes & $851 / 230$ & $0.51(0.27 ; 0.97)$ & $0.63(0.38 ; 1.07)$ & $0.80(0.46 ; 1.41)$ & $0.82(0.54 ; 1.25)$ & $0.72(0.26 ; 2.00)$ & $0.72(0.19 ; 2.69)$ \\
\hline
\end{tabular}

HRs were estimated from flexible parametric models with time since surgery as underlying time scale, not assuming proportional hazards (allowing HRs to vary over time)

Model 3: adjusted for age, sex, BMI, ASA, cancer stage, tumor level, neoadjuvant therapy, and year of surgery in a subcohort of patients operated between 2007 and 2010

$H R$, hazard ratio; $C I$, confidence interval 
Table 6 Hazard ratios for local recurrence and distant metastasis associated with planned defunctioning stoma in patients operated with low anterior resection for rectal cancer. Sensitivity analysis

\begin{tabular}{|c|c|c|c|c|}
\hline & \multicolumn{2}{|c|}{ Local recurrence } & \multicolumn{2}{|c|}{ Distant metastasis } \\
\hline & $N$ all/events & $\operatorname{HR}(95 \% \mathrm{CI})$ & $N$ all/events & $\operatorname{HR}(95 \% \mathrm{CI})$ \\
\hline \multicolumn{5}{|c|}{ Model 3 defunctioning stoma } \\
\hline No & $100 / 4$ & REF (1.00) & $100 / 24$ & REF (1.00) \\
\hline Yes & $851 / 21$ & $0.79(0.23 ; 2.71)$ & $851 / 148$ & $0.71(0.44 ; 1.14)$ \\
\hline
\end{tabular}

HRs were estimated from flexible parametric models with time since surgery as underlying time scale, not assuming proportional hazards (allowing HRs to vary over time)

Model 3: adjusted for age, sex, BMI, ASA, cancer stage, tumor level, neoadjuvant therapy, and year of surgery in a subcohort of patients operated between 2007 and 2010

$H R$, hazard ratio; $C I$, confidence interval

Funding Open access funding provided by Örebro University.

\section{Declarations}

Conflict of interest The authors declare no competing interests.

Open Access This article is licensed under a Creative Commons Attribution 4.0 International License, which permits use, sharing, adaptation, distribution and reproduction in any medium or format, as long as you give appropriate credit to the original author(s) and the source, provide a link to the Creative Commons licence, and indicate if changes were made. The images or other third party material in this article are included in the article's Creative Commons licence, unless indicated otherwise in a credit line to the material. If material is not included in the article's Creative Commons licence and your intended use is not permitted by statutory regulation or exceeds the permitted use, you will need to obtain permission directly from the copyright holder. To view a copy of this licence, visit http://creativecommons.org/licenses/by/4.0/.

\section{References}

1. Heald RJ, Husband EM, Ryall RD (1982) The mesorectum in rectal cancer surgery-the clue to pelvic recurrence? Br J Surg 69(10): 613-616

2. Kapiteijn E, Marijnen CA, Nagtegaal ID, Putter H, Steup WH, Wiggers $T$ et al (2001) Preoperative radiotherapy combined with total mesorectal excision for resectable rectal cancer. N Engl J Med 345(9):638-646

3. MacFarlane JK, Ryall RD, Heald RJ (1993) Mesorectal excision for rectal cancer. Lancet 341(8843):457-460

4. McDermott FD, Heeney A, Kelly ME, Steele RJ, Carlson GL, Winter DC (2015) Systematic review of preoperative, intraoperative and postoperative risk factors for colorectal anastomotic leaks. Br J Surg 102(5):462-479

5. Paun BC, Cassie S, MacLean AR, Dixon E, Buie WD (2010) Postoperative complications following surgery for rectal cancer. Ann Surg 251(5):807-818
6. Schlesinger NH, Smith H (2020) The effect of a diverting stoma on morbidity and risk of permanent stoma following anastomotic leakage after low anterior resection for rectal cancer: a nationwide cohort study. Int J Color Dis 35:1903-1910

7. Matthiessen P, Hallbook O, Rutegard J, Sjodahl R (2006) Population-based study of risk factors for postoperative death after anterior resection of the rectum. Br J Surg 93(4):498-503

8. Snijders HS, Wouters MW, van Leersum NJ, Kolfschoten NE, Henneman D, de Vries AC et al (2012) Meta-analysis of the risk for anastomotic leakage, the postoperative mortality caused by leakage in relation to the overall postoperative mortality. Eur J Surg Oncol 38(11):1013-1019

9. Huser N, Michalski CW, Erkan M, Schuster T, Rosenberg R, Kleeff J et al (2008) Systematic review and meta-analysis of the role of defunctioning stoma in low rectal cancer surgery. Ann Surg 248(1):52-60

10. Matthiessen P, Hallbook O, Rutegard J, Simert G, Sjodahl R (2007) Defunctioning stoma reduces symptomatic anastomotic leakage after low anterior resection of the rectum for cancer: a randomized multicenter trial. Ann Surg 246(2):207-214

11. Phan K, Oh L, Ctercteko G, Pathma-Nathan N, El Khoury T, Azam $\mathrm{H}$ et al (2019) Does a stoma reduce the risk of anastomotic leak and need for re-operation following low anterior resection for rectal cancer: systematic review and meta-analysis of randomized controlled trials. J Gastrointest Oncol 10(2):179-187

12. den Dulk M, Marijnen CA, Collette L, Putter H, Pahlman L, Folkesson J et al (2009) Multicentre analysis of oncological and survival outcomes following anastomotic leakage after rectal cancer surgery. Br J Surg 96(9):1066-1075

13. Tan WS, Tang CL, Shi L, Eu KW (2009) Meta-analysis of defunctioning stomas in low anterior resection for rectal cancer. Br J Surg 96(5):462-472

14. Gastinger I, Marusch F, Steinert R, Wolff S, Koeckerling F, Lippert $\mathrm{H}$ (2005) Protective defunctioning stoma in low anterior resection for rectal carcinoma. Br J Surg 92(9):1137-1142

15. den Dulk M, Smit M, Peeters KC, Kranenbarg EM, Rutten HJ, Wiggers T, Putter H, van de Velde C, Dutch Colorectal Cancer Group (2007) A multivariate analysis of limiting factors for stoma reversal in patients with rectal cancer entered into the total mesorectal excision (TME) trial: a retrospective study. Lancet Oncol 8(4):297-303

16. Floodeen H, Lindgren R, Matthiessen P (2013) When are defunctioning stomas in rectal cancer surgery really reversed? Results from a population-based single center experience. Scand J Surg 102(4):246-250

17. Gessler B, Haglind E, Angenete E (2012) Loop ileostomies in colorectal cancer patients-morbidity and risk factors for nonreversal. $\mathrm{J}$ Surg Res 178(2):708-714

18. Giannakopoulos GF, Veenhof AA, van der Peet DL, Sietses C, Meijerink WJ, Cuesta MA (2009) Morbidity and complications of protective loop ileostomy. Color Dis 11(6):609-612

19. Holmgren K, Kverneng Hultberg D, Haapamaki MM, Matthiessen P, Rutegard J, Rutegard M (2017) High stoma prevalence and stoma reversal complications following anterior resection for rectal cancer: a population-based multicentre study. Color Dis 19(12): $1067-1075$

20. Kaidar-Person O, Person B, Wexner SD (2005) Complications of construction and closure of temporary loop ileostomy. J Am Coll Surg 201(5):759-773

21. Sharma A, Deeb AP, Rickles AS, Iannuzzi JC, Monson JR, Fleming FJ (2013) Closure of defunctioning loop ileostomy is associated with considerable morbidity. Color Dis 15(4):458-462 
22. Espin E, Ciga MA, Pera M, Ortiz H (2015) Oncological outcome following anastomotic leak in rectal surgery. Br J Surg 102(4):416422

23. Smith JD, Paty PB, Guillem JG, Temple LK, Weiser MR, Nash GM (2012) Anastomotic leak is not associated with oncologic outcome in patients undergoing low anterior resection for rectal cancer. Ann Surg 256(6):1034-1038

24. Koedam TWA, Bootsma BT, Deijen CL, van de Brug T, Kazemier G, Cuesta MA et al (2020) Oncological outcomes after anastomotic leakage after surgery for colon or rectal cancer: increased risk of local recurrence. Ann Surg

25. Mirnezami A, Mirnezami R, Chandrakumaran K, Sasapu K, Sagar P, Finan P (2011) Increased local recurrence and reduced survival from colorectal cancer following anastomotic leak: systematic review and meta-analysis. Ann Surg 253(5):890-899

26. Pahlman L, Bohe M, Cedermark B, Dahlberg M, Lindmark G, Sjodahl R et al (2007) The Swedish rectal cancer registry. Br J Surg 94(10): 1285-1292

27. Jorgren F, Johansson R, Damber L, Lindmark G (2010) Risk factors of rectal cancer local recurrence: population-based survey and validation of the Swedish rectal cancer registry. Color Dis 12(10):977986

28. Moberger P, Skoldberg F, Birgisson H (2018) Evaluation of the Swedish Colorectal Cancer Registry: an overview of completeness, timeliness, comparability and validity. Acta Oncol 57(12):16111621

29. Swedish National Board of Health and Welfare, Swedish Cause of Death register, https://www.socialstyrelsen.se/en/search-results/? $\mathrm{q}=$ cause+of + death .2019

30. Royston P, Parmar MK (2002) Flexible parametric proportionalhazards and proportional-odds models for censored survival data, with application to prognostic modelling and estimation of treatment effects. Stat Med 21(15):2175-2197

31. Royston PLP (2011) Flexible parametric survival analysis using Stata: beyond the Cox model. Stata Press

32. Rutegard M, Kverneng Hultberg D, Angenete E, Lydrup ML (2017) Substantial underreporting of anastomotic leakage after anterior resection for rectal cancer in the Swedish Colorectal Cancer Registry. Acta Oncol 56(12):1741-1745

33. Mrak K, Uranitsch S, Pedross F, Heuberger A, Klingler A, Jagoditsch M, Weihs D, Eberl T, Tschmelitsch J (2016) Diverting ileostomy versus no diversion after low anterior resection for rectal cancer: a prospective, randomized, multicenter trial. Surgery. 159(4):1129-1139

34. Bostrom P, Haapamaki MM, Rutegard J, Matthiessen P, Rutegard M (2019) Population-based cohort study of the impact on postoperative mortality of anastomotic leakage after anterior resection for rectal cancer. BJS Open 3(1):106-111

35. Hain E, Maggiori L, Manceau G, Mongin C (2017) Prost AlDJ, Panis Y. Oncological impact of anastomotic leakage after laparoscopic mesorectal excision. Br J Surg 104(3):288-295

36. Jang JH, Kim HC, Huh JW, Park YA, Cho YB, Yun SH, Lee WY, Yu JI, Park HC, Park YS, Park JO (2019) Anastomotic leak does not impact oncologic outcomes after preoperative chemoradiotherapy and resection for rectal cancer. Ann Surg 269(4):678-685

37. Floodeen H, Hallbook O, Hagberg LA, Matthiessen P (2017) Costs and resource use following defunctioning stoma in low anterior resection for cancer - a long-term analysis of a randomized multicenter trial. Eur J Surg Oncol 43(2):330-336

Publisher's note Springer Nature remains neutral with regard to jurisdictional claims in published maps and institutional affiliations. 